\title{
Is inflammatory chronic obstructive pulmonary disease a coronary heart disease risk equivalent? A longitudinal analysis of the third National Health and Nutrition Examination Survey (NHANES III), 1988-1994
}

Donna R Parker ${ }^{1,2,3^{*}+}$, Jonathan Liu${ }^{4+}$, Mary B Roberts ${ }^{1+}$ and Charles B Eaton ${ }^{1,2,3+}$

\begin{abstract}
Background: Evidence suggests that there is an association between chronic obstructive pulmonary disease (COPD) and coronary heart disease (CHD). An important etiological link between COPD and CHD may be an underlying systemic inflammatory process. Given that COPD patients are at greater risk of cardiovascular mortality, understanding the burden of CHD on COPD patients could permit future risk attenuation.

Methods: Longitudinal cohort analyses of the Third National Health and Nutrition Examination Survey from 1988-1994 were performed. 3,681 individuals $\geq 40$ years of age with good quality spirometry data were included. Participants were divided into 5 groups: 1) no COPD, no CHD; 2) COPD without inflammation, no CHD; 3) COPD with inflammation, no CHD; 4) CHD only, and 5) CHD + COPD. A novel "inflammatory" COPD designation included those with COPD and clinical evidence of inflammation (i.e., CRP $\geq 95.24 \mathrm{nmol} / \mathrm{L}$ ).

Results: The risk for CHD mortality was significant only for the CHD group (HR 5.56, 95\% Cl 3.24-9.55) and the COPD + CHD group (HR 5.02, 95\% Cl 2.83-8.90). Similarly, the risk for cardiovascular disease (CVD) mortality was significant only for the CHD group ( $\mathrm{HR} 4.25,95 \% \mathrm{Cl}$ 2.70-6.69) and the CHD + COPD group (HR 4.12, 95\% Cl 2.60-6.54) after adjusting for nonmodifiable CHD risk factors (age, gender, race/ethnicity, family history of CHD). After adjusting for modifiable CHD risk factors (diabetes, BMI, physical activity, systolic blood pressure, cholesterol, and smoking), hazard ratios of the two groups remained similar but attenuated. For total mortality, the risk was significant for the four groups: the non-inflammatory COPD group; the COPD with inflammation group, the CHD group, and the COPD + CHD group.

Conclusions: Our study did not confirm that inflammatory COPD may be a CHD risk equivalent. However, due to the small size of the "inflammatory" COPD group, further prospective replication and validation is needed. Moreover, given that COPD results from inflammation, the systemic inflammation associated with COPD may have worsened comorbid conditions and may have lead to the increased total mortality found in the COPD with inflammation and COPD + CHD groups which requires further investigation.
\end{abstract}

\footnotetext{
* Correspondence: Donna_Parker@brown.edu

${ }^{\dagger}$ Equal contributors

'Brown Center for Primary Care and Prevention, Memorial Hospital of Rhode

Island, Pawtucket, USA

${ }^{2}$ Department of Family Medicine, Alpert Medical School of Brown University,

Providence, USA

Full list of author information is available at the end of the article
} 


\section{Background}

Chronic obstructive pulmonary disease (COPD) is an increasingly prevalent disease affecting 11.8 million people in the United States with evidence that it is underdiagnosed and may actually affect as many as 24 million individuals [1,2]. According to the Centers for Disease Control and Prevention (CDC), COPD recently overtook cerebrovascular diseases to become the third leading cause of death in the US, lagging only behind diseases of the heart and malignant neoplasms [3]. Of concern is that while COPD was originally predicted to reach third place by 2020, this was achieved in 2008 [4]. In fact, while the death rate from heart disease and stroke has dropped, COPD mortality rates doubled from 1970 to 2002 [5]. COPD not only contributes to morbidity and mortality but also represents a large economic burden to the US, with a 2010 estimated cost of $\$ 49.9$ billion [6].

The causes of death in COPD remain poorly understood, as studies reveal conflicting data. Etiologies such as lung cancer [7], respiratory failure [8], and cardiovascular disease [9], have all been found to be the most common cause of death in COPD patients. Death from COPD itself was found to be the most common cause (59.8\%) in one large population study from England with diseases of the circulatory system in second place [10]. Further, while death from respiratory disease and lung cancer are falling in COPD patients, death due to circulatory system causes is on the rise [11]. In fact, evidence suggests that patients with COPD may have a two to threefold increased risk for coronary heart disease death.

Research has revealed that COPD has been found to be associated with persistent low-grade systemic inflammation [12,13]. Systemic inflammation is present not only in individuals with reduced lung function but is also present in various other chronic diseases including coronary heart disease (CHD) $[14,15]$. Given the burden of lung and cardiovascular diseases (CVD) and emerging data suggesting a direct link between lung injury and inflammation and CHD, more research is needed to quantify the burden that CHD represents in individuals with COPD. For this study, we examined this association using data from the Third National Health and Nutrition Examination Survey (NHANES III), 1988-1994. We hypothesize that COPD is not only a risk factor for $\mathrm{CHD}$ but may, in fact, be a CHD risk equivalent.

\section{Methods}

\section{Study population}

NHANES III is a cross-sectional survey conducted between 1988 and 1994 by the National Center for Health Statistics (NCHS). NHANES III provides a nationally valid estimate of health and nutrition status among a representative group of civilian, noninstitutionalized US residents. Participants signed a consent form during the survey. NHANES Institutional Review Board (IRB) approval was obtained.

In order to provide accurate estimates, young children, the elderly, non-Hispanic blacks and Mexican Americans were oversampled. Sampling methods and design have been previously described [16,17]. Each participant was assigned a weight to allow for calculation of populationlevel estimates. NHANES III includes household interviews, physical exams in the Mobile Examination Center (MEC) and home examinations when participants could not reach the MEC.

Since COPD is uncommon in younger age groups, we limited our study population to participants $\geq 40$ years old with good quality, reliable spirometry data based on the criteria of the American Thoracic Society [18]. Exclusion criteria included individuals $<40$ years old, pregnant women, Asians (due to a limited number), home-assessed or unreliable spirometry, and a positive response to either of the following questions ("Have you had a cough, cold, or other acute illness in the past few days?" or "In the past three weeks have you had any respiratory infections, such as flu, pneumonia, bronchitis, or a severe cold?"). Our study population included 3,681 individuals who met these eligibility criteria.

\section{Mortality follow-up}

We evaluated coronary heart disease as well as cardiovascular disease and all-cause mortality as outcomes. Mortality follow-up data for NHANES III participants was available through December 31, 2006. Mortality status was obtained through the National Death Index (NDI) via probabilistic record matching conducted by the NCHS. Matching criteria included social security number, first and last name, middle initial, birth date, gender, race, marital status, state of birth and state of residency [19]. Mortality due to $\mathrm{CHD}$ as the primary cause of death was classified by using the International Classification of Disease $10^{\text {th }}$ Revision (ICD-10) 120.0125.9. Mortality due to CVD was classified by ICD-10 codes: $120.0-125.9,160-178$ (ischemic stroke). Number of months follow-up was determined from the "Person Months of Follow-up from Interview Date" variable in the mortality dataset, which was used in the time to death analysis [20].

\section{Measurements and variables}

In depth documentation of NHANES III laboratory and sample collection methods have been previously described and are briefly outlined below [21].

Age, gender and race information were collected during the home interview. Race was self-classified as white, black, non-black Hispanic or other. The self-report of physical activity included a questionnaire that evaluated the frequency and intensity of leisure time physical 
activities including dancing, jogging, running, bicycling, swimming, aerobics, and other activities. Intensity of the physical activity was expressed as a weekly metabolic equivalent (MET). METs are defined by increasing energy expenditure with MET = 1 corresponding to the resting metabolic rate and $\mathrm{MET}=10$ representing running at 6 mph [22].

Insurance status was determined during the home interview and includes coverage under Medicare, Medicaid, CHAMPUS, CHAMPVA, VA and other private or employer/union health plans. Marital status was measured as the percent of participants who were partnered, including those who were married or living as married. Education was measured as the percent of participants who did not complete high school ( $<12$ years of schooling). Income was determined as the percent of participants with a total combined family income over the last year amounting to less than $\$ 20,000$. Employment status was based on responses to questions asking if the participant had a job or business or if they worked within the past 2 weeks.

Blood pressure was reported as the average of five different measurements, taken by mercury sphygmomanometers (W. A. Baum Co., Copiague, NY) using standard technique [23]. The designation of hypertension (HTN) was given to those who were taking anti-hypertensive medications or those with a positive response to the question "Were you told on 2 or more different visits that you had hypertension, also called high blood pressure?"

Diabetes status was defined by self-report or prior diabetic medication use. BMI was calculated as weight in kilograms divided by the square of height in meters with height rounded to the nearest $0.1 \mathrm{~cm}$ and weight to $0.01 \mathrm{~kg}$.

Smoking status was divided into several categories including: current smokers, past smokers, never smokers and ever smokers. Current smokers were defined by answering "yes" to questions: "Do you smoke cigarettes now?" and "Have you smoked at least 100 cigarettes in your lifetime?" Past smokers included those who do not smoke cigarettes now but smoked over 100 cigarettes in their lifetime. Never smokers were those who smoked less than 100 cigarettes in their lifetime. Ever smokers were determined by combining past and current smokers. Number of cigarettes per day was also measured. A participant was considered exposed to environmental tobacco smoke (second-hand smoke) if he/she currently smoked or lived with someone who smoked in the home.

Alcohol consumption was assessed through questions from the household interview asking how many times over the past month participants drank beer, wine and hard liquor. Frequency across all three alcohol types was summated and expressed as number of drinks per week and dichotomized to "any alcohol" or none.
Clinical symptoms of cough and phlegm were determined by a positive response to questions which asked participants if they coughed or produced phlegm on most days for 3 consecutive months or more. Shortness of breath was assessed through interview as being "troubled by shortness of breath when hurrying on level ground or walking up a slight hill".

Diagnosis of COPD was based on spirometry. Spirometry was performed in a designated room in the MEC devoted to spirometry using a customized Ohio Sensormed 827 dry rolling seal spirometer [24]. Calibration was performed at the start of each session and participants were coached during the procedure so as to produce the best results. Participants were encouraged to blow for at least six seconds as required by ATS guidelines, thus measuring forced vital capacity (FVC). The session was complete when five acceptable trials were obtained, with a maximum of eight [24]. The tests were reviewed by two senior technicians and classified for reliability. All unacceptable maneuvers were excluded before reproducibility calculations were performed [24].

We used an FEV1/FVC ratio (forced expiratory volume in one second/forced vital capacity) of $<0.70$ to define airflow obstruction. Mild, moderate, severe, and very severe airflow obstruction were defined as respectively: stage $1-\mathrm{FEV} 1 \geq 80 \%$ of predicted; Stage $2-50 \% \leq$ FEV $1<80 \%$ predicted; Stage $3-30 \% \leq$ FEV $1<50 \%$ predicted; and Stage 4 -FEV1 $<30 \%$ predicted based on the GOLD COPD Guidelines [25] and the predicted FEV1 based on the equation developed by Hankinson et al. [26].

CHD diagnosis was based on an affirmative response to the interview question: "Has your doctor ever told you that you had a heart attack?" Participants were classified into CHD risk groups based on the number of CHD risk factors or risk equivalents they had [27].

Laboratory analyses: fasting blood samples were obtained in the MEC or during the home interview. All blood samples were frozen and shipped on dry ice to laboratories for analysis. Upon arrival at the laboratories, frozen specimens were initially stored at $-20^{\circ} \mathrm{C}$, refrigerated samples were stored at $4-8^{\circ} \mathrm{C}$, and frozen specimens with delayed analysis were stored at $-70^{\circ} \mathrm{C}$ or lower [21].

Triglycerides (TG), HDL cholesterol (HDL-c), and total cholesterol (TC) analyses were performed by the Hitachi 704 Analyzer (Boehringer Mannheim Diagnostics, Indianapolis, IN). LDL cholesterol (LDL-c) was not calculated from these measurements because a certain percentage of the population did not fast prior to blood draw. Non-HDL was calculated as the difference between total cholesterol and HDL, which may be a superior predictor of cardiovascular events compared to LDL-c [28].

White blood cell (WBC) count was determined by the Coulter Counter Model S-PLUS JR with Coulter histogram differential, an automated hematology analyzer. 
Homocysteine (Hcy) level was determined by reverse-phase high-performance liquid chromatography (HPLC) and fluorescence detection [29]. Due to NHANES limitations, Hcy testing was performed only on participants $\geq 12$ years of age in phase II (1991-1994).

Fibrinogen was measured by the Coagamate XC plus automated coagulation analyzer (Organon Teknika, Durham, NC). Ferritin was measured using the BioRad Laboratories "Quantimune Ferritin IRMA" 1000 kit (Hercules, CA). Hemoglobin A1c was measured by the Bio-Rad DIAMAT glycosylated hemoglobin analyzer system, using HPLC principles (Bio-Rad Laboratories, Hercules, CA).

Serum C-Reactive Protein (CRP) is a marker of systemic inflammation and a validated independent risk factor for CHD [30]. It was quantified via latex-enhanced nephelometry using the Behring Nephelometer Analyzer System (Behring Diagnostics Inc., Somerville, NJ). Since most participants had CRP values below the lowest detectable level $(20.95 \mathrm{nmol} / \mathrm{L})$, CRP was dichotomized into low $(<95.24 \mathrm{nmol} / \mathrm{L})$ and high $(\geq 95.24 \mathrm{nmol} / \mathrm{L})$ levels which are consistent with previous NHANES III categorization $[31,32]$. Low levels were used to define the noninflammatory COPD group and high levels were used to define the inflammatory COPD group.

Diagnostic groups used for analyses. Participants were divided into five exposure groups based upon their COPD status from spirometry testing, their CRP level, and their self-reported CHD status. Participants whose spirometry results indicated no COPD were placed into Group 1- no COPD and no CHD ("Healthy"individuals free of hypertension, diabetes, and arthritis); participants who had COPD and had no inflammation (CRP $<95.24 \mathrm{nmol} / \mathrm{L}$ ) [31,32] were included in Group 2 ("non-Inflammatory COPD"); participants who had COPD and had inflammation (CRP $\geq 95.24 \mathrm{nmol} / \mathrm{L})[31,32]$ were included in Group 3 ("inflammatory COPD"); participants who reported "yes" to the question "Has a doctor ever told you that you had a heart attack?" and did not have COPD based on spirometry results were placed in Group 4 (the "CHD" Group); and participants who reported "yes" to the question "Has a doctor ever told you that you had a heart attack?" and had COPD based on spirometry results were placed in Group 5 (the "CHD +COPD" Group).

\section{Statistical analysis}

Descriptive statistics were used to examine demographics, CHD risk factors and inflammatory biomarkers of the five study groups. Analysis of variance and chi-square tests were used to evaluate differences in prevalence of continuous and categorical risk factors, respectively, among the five study groups while adjusting for the complex sampling design in NHANES III.
Cox proportional hazards models were used to examine the time to CHD mortality. In addition, we explored the relation between COPD subgroups and CVD as well as COPD subgroups and all-cause mortality after adjusting for the confounding effect of CHD risk factors and inflammatory biomarkers including age, gender, race/ethnicity, family history of $\mathrm{CHD}$, diabetes, $\mathrm{BMI}$, physical activity level, cholesterol ratio, current smoking, household income, education, and blood pressure medications. Tests for violations in the proportional hazards assumptions were also conducted and found to be insignificant.

The adjusted hazards ratios and their 95\% confidence intervals were used to measure the association between COPD subgroups and (CHD, CVD and all-cause) mortality. Statistical analyses were performed using SAS-callable (version 9.2, SAS Institute Inc., Cary, NC) SUDAAN version 11.0.1 (Research Triangle Institute, Research Triangle Park, NC).

\section{Results}

We first examined the characteristics of the five study groups that are presented in Table 1 . The CHD only group included predominantly males $(62.4 \%)$ whereas the "inflammatory" COPD group included mostly females (54.6\%). Age, race, education, insurance status, income, employment, and smoking status were significantly different among the five groups (group $\mathrm{p}<0.001$ ). Only marital status and alcohol were non-significant among the five groups. Regarding smoking, the Healthy group had the lowest prevalence of ever smokers (52.8\%). For the remaining groups, the CHD + COPD group had the highest prevalence of ever smokers $(88.7 \%)$ while the CHD group had the lowest prevalence of ever smokers (65.4\%) $(\mathrm{p}<0.001)$. The non-inflammatory and inflammatory COPD groups, however, had more current smokers than the CHD group $(29.0 \%, 38.6 \%$ and $17.4 \%$, respectively, $\mathrm{p}<0.001$ ). In terms of respiratory symptoms (cough or phlegm 3+ months), individuals in the inflammatory COPD group self-reported more symptoms (29.1\%) compared to the non-inflammatory COPD group (17.1\%), $\mathrm{p}=0.028$, despite nearly equivalent FEV1/FVC ratios.

CHD risk factors and inflammatory biomarkers among the five study groups are presented in Table 2. All variables were significantly different among the four groups. Among the five groups, body mass index (BMI) was lowest in the non-inflammatory COPD group while hypertension and diabetes prevalence rates and triglycerides and TC/HDL levels were significantly higher in the $\mathrm{CHD}+\mathrm{COPD}$ group compared to the COPD groups, except for HDL. HDL, which has an inverse relation, was lower in the $\mathrm{CHD}+$ COPD group compared to the COPD groups. Of the inflammatory biomarkers, CRP, ferritin, fibrinogen, and WBC were elevated in the inflammatory COPD group $(\mathrm{p}<0.001)$. 
Table 1 Characteristics of the five study groups

\begin{tabular}{|c|c|c|c|c|c|c|c|}
\hline & & "Healthy" & Non-inflammatory COPD & Inflammatory COPD & CHD only & CHD + COPD & Group p-value \\
\hline $\bar{N}$ & & 2,107 & 1,100 & 118 & 235 & 121 & \\
\hline Weighted N & & $26,684,256$ & $11,704,624$ & $1,147,035$ & $1,992,045$ & $1,109,152$ & \\
\hline \multirow[t]{2}{*}{ Gender (\%) } & Male & 47.9 & 57.0 & 45.4 & 62.4 & 73.7 & $<0.001$ \\
\hline & Female & 52.1 & 43.0 & 54.6 & 37.6 & 26.3 & \\
\hline \multirow[t]{6}{*}{ Age (\%) } & $40-49$ & 56.8 & 18.8 & 5.8 & 12.3 & 3.3 & $<0.001$ \\
\hline & $50-59$ & 24.6 & 22.2 & 24.6 & 20.3 & 13.5 & \\
\hline & $60-69$ & 11.3 & 28.5 & 29.1 & 27.7 & 28.9 & \\
\hline & $70-79$ & 5.5 & 22.4 & 33.7 & 28.6 & 36.4 & \\
\hline & $80+$ & 1.8 & 8.2 & 6.8 & 11.1 & 18.0 & \\
\hline & $60+$ years & 18.6 & 59.1 & 69.6 & 67.4 & 83.3 & $<0.001$ \\
\hline \multirow[t]{4}{*}{ Race (\%) } & White & 85.1 & 91.0 & 83.7 & 86.0 & 96.7 & $<0.001$ \\
\hline & Black & 6.8 & 5.1 & 8.7 & 9.2 & 2.5 & \\
\hline & Hispanic & 8.0 & 3.9 & 7.6 & 4.8 & 0.8 & \\
\hline & Minority & 14.8 & 9.0 & 16.3 & 15.0 & 3.3 & \\
\hline Education (\%) & $<$ High School & 18.9 & 30.4 & 36.0 & 36.0 & 40.7 & $<0.001$ \\
\hline Marital Status (\%) & Partnered & 76.8 & 72.9 & 62.9 & 74.6 & 72.3 & 0.138 \\
\hline Insured (\%) & & 92.4 & 95.6 & 98.9 & 97.1 & 97.5 & $<0.001$ \\
\hline Income (\%) & $<\$ 20 \mathrm{~K} /$ year & 19.8 & 35.5 & 50.9 & 42.3 & 41.9 & $<0.001$ \\
\hline Employed (\%) & & 77.6 & 47.6 & 32.7 & 38.1 & 28.2 & $<0.001$ \\
\hline Any Alcohol Consumption (\%) & & 89.0 & 89.9 & 90.5 & 86.6 & 87.9 & 0.727 \\
\hline Alcohol * Consumption & (\# drinks per week) & $3.8(0.3)$ & $3.9(0.5)$ & $6.7(3.3)$ & $2.8(0.7)$ & $3.6(1.3)$ & 0.466 \\
\hline \multirow[t]{4}{*}{ Smoking Status (\%) } & Never & 47.2 & 27.2 & 23.3 & 34.6 & 11.3 & $<0.001$ \\
\hline & Past & 34.6 & 43.8 & 38.2 & 48.0 & 69.3 & \\
\hline & Current & 18.2 & 29.0 & 38.6 & 17.4 & 19.4 & \\
\hline & Ever (Past + Current) & 52.8 & 72.8 & 76.8 & 65.4 & 88.7 & $<0.001$ \\
\hline No. cigarettes per day* & & $3.5(0.3)$ & $6.7(0.5)$ & $7.9(1.5)$ & $3.9(1.2)$ & $5.3(1.9)$ & $<0.001$ \\
\hline 10 pack-year smoking history (\%) & & 30.4 & 55.1 & 61.2 & 45.4 & 71.9 & $<0.001$ \\
\hline Exposure to ETS (\%) & & 30.4 & 38.0 & 46.9 & 28.3 & 29.0 & 0.004 \\
\hline Cough or phlegm, $3+$ months (\%) & & 7.9 & 17.1 & 29.1 & 10.8 & 19.5 & $<0.001$ \\
\hline Shortness of breath (\%) & & 16.5 & 34.4 & 50.3 & 54.6 & 48.9 & $<0.001$ \\
\hline FEV1/FVC ratio* & & $0.79(0.01)$ & $0.63(0.01)$ & $0.61(0.01)$ & $0.78(0.01)$ & $0.62(0.01)$ & $<0.001$ \\
\hline FEV1 $(m l)^{*}$ & & 3196 (26.6) & 2417 (39.2) & 1952 (94.3) & 2699 (82.3) & 2176 (75.8) & $<0.001$ \\
\hline FVC $(m l)^{*}$ & & 4069 (33.8) & $3823(57.3)$ & 3165 (128.7) & $3494(109.5)$ & 3503 (95.9) & $<0.001$ \\
\hline
\end{tabular}


Table 1 Characteristics of the five study groups (Continued)

\begin{tabular}{|c|c|c|c|c|c|c|c|}
\hline \multirow[t]{4}{*}{ COPD Severity (\%) } & None & 100.0 & 0.0 & 0.0 & 100.0 & 0.0 & $<0.001$ \\
\hline & Mild & 0.0 & 58.7 & 40.5 & 0.0 & 46.1 & \\
\hline & Moderate & 0.0 & 35.2 & 45.3 & 0.0 & 49.0 & \\
\hline & Severe & 0.0 & 6.1 & 14.2 & 0.0 & 4.9 & \\
\hline \multirow[t]{3}{*}{ Mortality (\%) } & $\mathrm{CHD}$ & 2.4 & 6.4 & 12.7 & 30.1 & 33.5 & $<0.001$ \\
\hline & CVD & 3.5 & 9.8 & 15.7 & 33.5 & 39.7 & $<0.001$ \\
\hline & All-cause & 11.3 & 40.4 & 57.7 & 62.8 & 69.2 & $<0.001$ \\
\hline No. months follow-up* & & $173(2.8)$ & $150(3.6)$ & $128(7.3)$ & $124(5.6)$ & $115(6.9)$ & $<0.001$ \\
\hline
\end{tabular}


Table 2 CHD risk factors and inflammatory biomarkers among the five study groups

\begin{tabular}{|c|c|c|c|c|c|c|c|}
\hline & & "Healthy" & $\begin{array}{r}\text { Non-inflammatory } \\
\text { COPD }\end{array}$ & $\begin{array}{r}\text { Inflammatory } \\
\text { COPD }\end{array}$ & CHD Only & CHD + COPD & $\begin{array}{r}\text { Group } \\
\text { p-value } \\
\end{array}$ \\
\hline Age $^{*}$ & & $50.9(0.5)$ & $62.2(0.7)$ & $65.6(1.3)$ & $65.1(1.1)$ & $69.6(1.0)$ & $<0.001$ \\
\hline $\mathrm{BMI}^{*}$ & & $26.4(0.1)$ & $26.2(0.2)$ & $27.9(0.7)$ & $28.5(0.8)$ & $26.4(0.3)$ & 0.002 \\
\hline Physical Activity (METS/week)* & & $116(4.4)$ & $108(5.8)$ & $66(8.5)$ & $128(12.8)$ & $123(17.7)$ & 0.008 \\
\hline HTN (\%) & & 0.0 & 27.2 & 43.6 & 54.4 & 55.3 & $<0.001$ \\
\hline SBP & & $122(0.4)$ & $133(0.8)$ & $139(2.1)$ & $138(1.4)$ & $139(2.5)$ & $<0.001$ \\
\hline DBP & & $75(0.3)$ & $76(0.4)$ & $75(1.1)$ & $75(0.9)$ & $73(1.4)$ & 0.373 \\
\hline Diabetes (\%) & & 0.0 & 7.1 & 4.4 & 20.4 & 15.9 & $<0.001$ \\
\hline $\mathrm{HbA} 1 \mathrm{c}$ & & $5.28(0.03)$ & $5.62(0.05)$ & $5.83(0.11)$ & $5.98(0.08)$ & $5.90(0.14)$ & $<0.001$ \\
\hline \multirow[t]{3}{*}{ Framingham Risk (\%) } & $<10 \%$ & 82.2 & 56.5 & 52.4 & 38.5 & 29.4 & $<0.001$ \\
\hline & $10-20 \%$ & 16.3 & 33.4 & 29.1 & 46.0 & 50.8 & \\
\hline & $>20 \%$ & 1.5 & 10.0 & 18.5 & 15.5 & 19.8 & \\
\hline \multirow[t]{5}{*}{ Risk Group (\%) } & CHD Equivalent & 1.5 & 18.2 & 22.1 & 100.0 & 100.0 & $<0.001$ \\
\hline & High & 11.9 & 19.4 & 18.5 & 0.0 & 0.0 & \\
\hline & Moderate & 14.6 & 21.0 & 20.2 & 0.0 & 0.0 & \\
\hline & Low & 71.0 & 40.7 & 36.4 & 0.0 & 0.0 & \\
\hline & $\mathrm{High}+\mathrm{CHD}$ & 13.4 & 37.6 & 40.6 & 100.0 & 100.0 & $<0.001$ \\
\hline \multicolumn{8}{|l|}{ Lipid Profiles* } \\
\hline Total cholesterol & $(\mathrm{mmol} / \mathrm{L})$ & $5.50(0.04)$ & $5.66(0.04)$ & $5.53(0.10)$ & $5.85(0.10)$ & $5.85(0.09)$ & $<0.001$ \\
\hline $\mathrm{HDL}$ & $(\mathrm{mmol} / \mathrm{L})$ & $1.34(0.02)$ & $1.32(0.02)$ & $1.34(0.07)$ & $1.20(0.05)$ & $1.18(0.04)$ & 0.002 \\
\hline Triglycerides & $(\mathrm{mmol} / \mathrm{L})$ & $1.57(0.04)$ & $1.71(0.04)$ & $1.86(0.11)$ & $2.07(0.09)$ & $2.26(0.19)$ & $<0.001$ \\
\hline $\mathrm{TC} / \mathrm{HDL}$ ratio & & $4.47(0.08)$ & $4.67(0.09)$ & $4.67(0.22)$ & $5.30(0.20)$ & $5.53(0.31)$ & $<0.001$ \\
\hline Non-HDL & $(\mathrm{mmol} / \mathrm{L})$ & $4.15(0.04)$ & $4.15(0.04)$ & $4.22(0.12)$ & $4.65(0.11)$ & $4.67(0.09)$ & $<0.001$ \\
\hline \multicolumn{8}{|l|}{ Inflammatory Biomarkers* } \\
\hline Homocysteine & (umol/L) & $9.45(0.23)$ & $11.59(0.58)$ & $12.85(1.86)$ & $11.94(0.55)$ & $11.58(0.65)$ & $<0.001$ \\
\hline CRP & $(\mathrm{mmol} / \mathrm{L})$ & $30.14(1.19)$ & $27.87 \quad(0.71)$ & $200.27(14.57)$ & $62.98(11.46)$ & $73.92(20.11)$ & $<0.001$ \\
\hline Ferritin & (pmol/L) & $296.09(11.16)$ & 355.37 (12.83) & 373.77 (37.54) & $334.66(29.30)$ & $342.82(43.24)$ & $<0.001$ \\
\hline Fibrinogen & (umol/L) & $8.30(0.10)$ & $8.78(0.11)$ & $12.21(0.50)$ & $9.48(0.27)$ & $9.75(0.42)$ & $<0.001$ \\
\hline WBC & $(\times 10 \wedge 3)$ & $6.71(0.06)$ & $7.37(0.14)$ & $8.45(0.33)$ & $7.47(0.24)$ & $7.66(0.32)$ & $<0.001$ \\
\hline
\end{tabular}

*mean \pm standard error.

CRP was significantly elevated in the inflammatory COPD group (200.27 nmol/L) compared to the CHD group $(62.98 \mathrm{nmol} / \mathrm{L})$ and $\mathrm{CHD}+\mathrm{COPD}$ group $(73.92 \mathrm{nmol} / \mathrm{L})$ ( $\mathrm{p}<0.001)$. Additionally, fibrinogen and WBC were also elevated in the inflammatory COPD group compared to the CHD and the CHD + COPD group ( $<<0.001$ AND $\mathrm{P}=0.009$, respectively) and the non-inflammatory COPD group $(\mathrm{p}<0.001$ and $\mathrm{p}=0.005)$.

The hazard ratios (HRs) of CHD mortality, CVD and all-cause mortality among the five study groups are presented in Table 3. In the fully-adjusted models, the risk for CHD mortality were similar for the "Healthy" and COPD without inflammation groups, intermediate risk for the COPD with inflammation group (HR 2.06, 95\% CI 0.84-5.04), and higher for the COPD + CHD group
(HR 3.89, 95\% CI 2.28-6.65) and CHD group (HR 4.55, 95\% CI 2.48-8.36). A similar pattern was found for CVD mortality. For all-cause mortality, the risk was significant and similar for the COPD with inflammation group (HR 2.01, 95\% CI 1.24-3.28), the CHD group (HR 2.48, 95\% CI 1.94-3.16) and the COPD and CHD group (HR 2.19, 95\% CI 1.63-2.95).

Figures 1a, b and c present the covariate adjusted Cox proportional hazards model survival curves for $\mathrm{CHD}$, CVD, and all-cause mortality respectively among the five study groups. The mortality rate curves for both CHD and CVD were similar and were accelerated for the CHD and CHD + COPD groups followed by the inflammatory COPD group. For all-cause mortality, the mortality rate curves were accelerated for $\mathrm{CHD}, \mathrm{CHD}+$ 
Table 3 Hazards ratios and associated $95 \%$ Cl for CHD, CVD, and all-cause mortality survival models

\begin{tabular}{|c|c|c|c|c|c|c|c|c|}
\hline \multirow[t]{2}{*}{ Model } & \multirow{2}{*}{$\begin{array}{c}\text { "Healthy" } \\
\text { (n=2107) [L1] }\end{array}$} & \multirow{2}{*}{$\begin{array}{l}\text { Non-inflammatory } \\
\text { COPD }(n=1100)[L 2]\end{array}$} & \multirow{2}{*}{$\begin{array}{l}\text { Inflammatory COPD } \\
(n=118) \\
{[\text { [L3] }}\end{array}$} & \multirow{2}{*}{$\begin{array}{l}\text { CHD only } \\
(n=235)[L 4]\end{array}$} & \multirow{2}{*}{$\begin{array}{l}\text { COPD + CHD } \\
(n=121)[L 5]\end{array}$} & \multicolumn{3}{|c|}{ Group comparison p-values } \\
\hline & & & & & & [L2] vs [L3] & [L3] vs [L4] & [L4] vs [L5] \\
\hline \multicolumn{9}{|l|}{ CHD Mortality } \\
\hline Crude & 1.00 & $3.20(2.22-4.61)$ & $7.81(3.10-19.66)$ & $18.91(11.85-30.19)$ & $23.20(12.85-41.89)$ & 0.043 & 0.044 & 0.426 \\
\hline Age Adjusted & 1.00 & $1.21(0.81-1.82)$ & $2.63(0.96-7.20)$ & $6.36(3.72-10.87)$ & $6.29(3.58-11.03)$ & 0.102 & 0.065 & 0.961 \\
\hline Non-modifiable Adjusted & 1.00 & $1.11(0.75-1.65)$ & $2.52(0.92-6.89)$ & $5.56(3.24-9.55)$ & $5.02(2.83-8.90)$ & 0.082 & 0.098 & 0.671 \\
\hline Full Model & 1.00 & $0.90(0.61-1.33)$ & $2.06(0.84-5.04)$ & $4.55(2.48-8.36)$ & $3.89(2.28-6.65)$ & 0.061 & 0.112 & 0.498 \\
\hline \multicolumn{9}{|l|}{ CVD Mortality } \\
\hline Crude & 1.00 & $3.37(2.38-4.79)$ & $6.60(2.93-14.85)$ & $14.53(9.60-22.00)$ & $18.81(11.14-31.76)$ & 0.080 & 0.029 & 0.269 \\
\hline Age Adjusted & 1.00 & $1.21(0.83-1.79)$ & $2.11(0.87-5.08)$ & $4.62(2.96-7.21)$ & $4.78(3.04-7.52)$ & 0.182 & 0.051 & 0.861 \\
\hline Non-modifiable Adjusted & 1.00 & $1.15(0.78-1.68)$ & $2.01(0.84-4.79)$ & $4.25(2.70-6.69)$ & $4.12(2.60-6.54)$ & 0.164 & 0.056 & 0.880 \\
\hline Full Model & 1.00 & $0.93(0.62-1.40)$ & $1.55(0.68-3.51)$ & $3.38(1.97-5.80)$ & $3.16(1.99-5.01)$ & 0.202 & 0.065 & 0.727 \\
\hline \multicolumn{9}{|l|}{ All-Cause Mortality } \\
\hline Crude & 1.00 & $4.30(3.51-5.26)$ & $7.55(4.65-12.25)$ & $8.55(6.61-11.07)$ & $10.30(7.21-14.71)$ & 0.007 & 0.561 & 0.299 \\
\hline Age Adjusted & 1.00 & $1.80(1.44-2.25)$ & $2.79(1.63-4.79)$ & $3.25(2.59-4.08)$ & $3.17(2.33-4.30)$ & 0.061 & 0.523 & 0.847 \\
\hline Non-modifiable Adjusted & 1.00 & $1.70(1.36-2.12)$ & $2.72(1.62-4.56)$ & $2.96(2.33-3.76)$ & $2.72(1.97-3.74)$ & 0.037 & 0.701 & 0.546 \\
\hline Full Model & 1.00 & $1.39(1.12-1.74)$ & $2.01(1.24-3.28)$ & $2.48(1.94-3.16)$ & $2.19(1.63-2.95)$ & 0.096 & 0.373 & 0.348 \\
\hline
\end{tabular}

Non-modifiable adjusted model covariates: age, gender, race/ethnicity, family history

Full model covariates: age, gender, race/ethnicity, household income, education, family history CHD, diabetes, BMI, physical activity level, SBP, cholesterol ratio, current smoking, BP medications. 


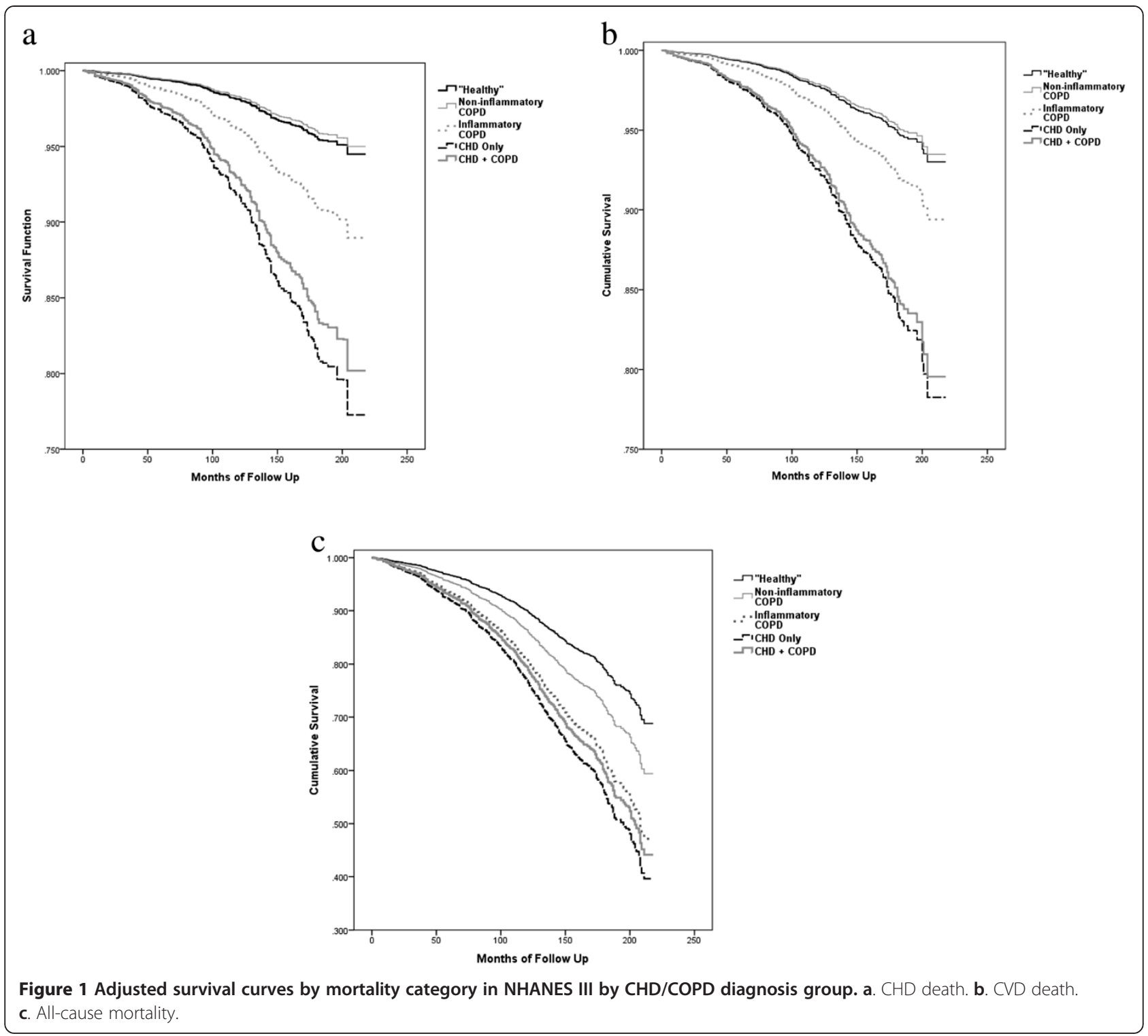

COPD, and COPD with inflammation compared to noninflammatory COPD and the "Healthy" group

\section{Discussion}

To our knowledge, this is the first study to examine the association between subgroups of COPD and CHD, CVD and all-cause mortality. Our findings suggest that CHD, CVD and all-cause mortality rates did not differ significantly between individuals with $\mathrm{CHD}$ and individuals with CHD + COPD. Although the mortality rates for individuals with COPD with inflammation were lower, of interest was that the inflammatory COPD group included mainly women who, despite having similar pulmonary function test parameters as the non-inflammatory COPD group, experienced more cough and phlegm production. Additionally, they were less physically active and had elevated inflammatory biomarkers compared to those with CHD and those with CHD + COPD. Furthermore, a consistent trend of monotonically increasing $\mathrm{CHD}$ and CVD mortality rates was observed when the "Healthy", noninflammatory COPD, inflammatory COPD, CHD + COPD and $\mathrm{CHD}$ groups were compared in that order.

The hazard ratios were not significantly different between the CHD group and the CHD + COPD group and were greater compared to individuals with COPD with inflammation. In contrast, all-cause mortality was equal among those in the inflammatory COPD group, the CHD group, and the CHD + COPD group. However, given the small number of individuals in the inflammatory COPD group $(\mathrm{n}=118)$, we may not have had sufficient power to examine the association for $\mathrm{CHD}$ and CVD which requires further investigation. 
Survival curve analysis also showed that inflammatory COPD, CHD only, and CHD + COPD follow virtually the same curve for all-cause mortality. Inflammatory COPD had a worse survival curve compared to noninflammatory COPD in the all-cause mortality model, suggesting that those with inflammatory COPD have an accelerated mortality rate compared to individuals with non-inflammatory COPD.

In a previous study of NHANES III participants who were fifty years of age and older, Sin and Man examined whether CRP and other systemic inflammatory markers were present in individuals with chronic airflow obstruction that were also associated with cardiac injury (as measured by a Cardiac Infarction Injury Score based on EKG findings). They reported that severe airway obstruction, in the setting of elevated CRP, increased risk of cardiac injury almost two-fold [12]. Their findings suggest "that the systemic inflammation associated with moderate to severe airflow obstruction and an increased risk of cardiac injury may partially explain the high rates of CVD complication in COPD" [12].

Our study did not confirm this finding except for total mortality. However, our study differs in that we included participants $\geq 40$ years old while Sin and Man included those $\geq 50$ years old and used EKG criteria as a measure of heart disease rather than measuring mortality as the outcome. Furthermore, as previous mentioned, our sample included only a small number of individuals in the inflammatory COPD group and we may not have had sufficient power to examine this association.

\section{Inflammation a possible underlying factor}

As mentioned earlier, COPD is increasingly being identified as a systemic disease with comorbidities extending beyond the lungs. These systemic sequelae include cardiovascular disease, diabetes, osteoporosis, anemia, cachexia, hypertension, cancer and depression [33]. Systemic inflammation may be the common pathway among these diseases, explaining their high rate of prevalence together [33]. Evidence for systemic inflammation is rapidly expanding. COPD patients exhibit elevated levels of inflammatory biomarkers including CRP, TNF- $\alpha$, fibrinogen, leukocytes, IL-6, and IL-8 [34,35] suggesting that COPD may be similar to other diseases associated with systemic inflammation including CAD, peripheral arterial disease, osteoporosis and diabetes [14]. In fact, the systemic inflammation may initiate or worsen the comorbid diseases and may potentiate the morbidity of COPD that could lead to an increase in total mortality which we observed in this study.

Current goals of COPD treatment include decreasing exacerbation frequency, improving symptoms and raising exercise tolerance [25]. Medications used to achieve these ends include inhaled $\beta$-2 agonists, inhaled anticholinergics, corticosteroids, theophylline, and oxygen [25]. This paradigm, however, ignores potentially large gains in mortality and comorbidity reduction by focusing treatment solely on the lung. Given the increased risk associated with COPD, therapeutic interventions may help to improve cardiovascular mortality.

If systemic inflammation is a common pathway for both CHD and COPD with inflammation, one approach may be expanded use of statins. Besides lowering cholesterol, statins display anti-inflammatory and immunomodulatory effects [36]. The benefits of statin therapy in individuals with normal lipid values but systemic inflammation have been recently demonstrated in the JUPITER Study. They found that rosuvastatin significantly reduced the incidence of cardiovascular events $(\mathrm{HR}=0.56,95 \%$ CI $0.46-0.69, \mathrm{p}<0.0001)$, alluding to the potential antiinflammatory benefit of statins [37].

Whether this benefit may also be observed in COPD patients was studied by Mancini et al. who showed a significant reduction in mortality among high-risk COPD patients on statins (RR 0.50, 95\% CI 0.40-0.62; p <0.0001) and an improved benefit among those taking both statins and an ACEI/ARB (RR 0.42, 95\% CI 0.33-0.52, p < 0.0001) [38]. These benefits persisted among COPD patients regardless of steroid use [38]. This finding was corroborated by Mortensen et al. who showed a decrease in 90-day mortality post-discharge after COPD exacerbation in patients using statins (OR 0.51, 95\% CI 0.40-0.64) and ACEI/ARB (OR 0.55, 95\% CI 0.46-0.66) prior to admission [39].

\section{Study strengths and limitations}

Our study was limited by several factors. Mortality data was obtained through the National Death Index and the cause of death reported on death certificates may suffer from inaccuracies or misclassification. Current GOLD guideline recommendations for spirometry-based diagnosis of COPD have been criticized for not adequately accounting for age-related changes in lung function and inter-subject spirometry performance variability, resulting in misdiagnosis in the elderly [40]. By using GOLD guidelines, we were subject to this possibility.

Additionally, since the diagnosis of COPD was based on pre-bronchodilator spirometry, it is possible that there may have been an overestimation of COPD. However, this overestimation was probably distributed equally across the five diagnostic groups. We were limited by the NHANES data set and used mortality as a measure for CHD risk instead of new CHD events (i.e. MI), which may be of future interest. Finally, as previously mentioned, we note a small sample size $(n=118)$ in the inflammatory COPD subgroup. The sample, however, represents a weighted $n=1,147,035$ people in the US. Future work should investigate whether this finding is replicable in other cohorts. 
Given that NHANES III is a population-based survey, one strength of our study is that our results are representative of the US population and are thereby generalizable. NHANES III also oversampled African Americans and Hispanics to allow better estimation of the true US population. Another strength is the inclusion of numerous $\mathrm{CHD}$ risk factors and inflammatory biomarkers in our analysis.

\section{Conclusions}

Our findings did not show that inflammatory COPD may be a CHD risk equivalent but due to the small sample requires additional investigation. Additionally, given that COPD results from inflammation, the systemic inflammation associated with COPD may have worsened comorbid conditions and may have lead to the increased total mortality found in the COPD with inflammation and CHD + COPD groups which requires further investigation. Furthermore treatment of COPD may require not only treatment of the systematic inflammation but also treatment of the associated comorbidites.

\section{Competing interests}

The authors declare that they have no competing interests.

\section{Authors' contributions}

All authors made substantial contributions to the manuscript. DRP was involved in the design of the study and drafting the manuscript; $J$ also participated in the design and drafting the manuscript; MBR participated in the design of the study and performed the statistical analyses and CBE conceived the study, participated in its design, and helped draft the manuscript and all authors read and approved the submitted manuscript.

\section{Author details}

'Brown Center for Primary Care and Prevention, Memorial Hospital of Rhode Island, Pawtucket, USA. ${ }^{2}$ Department of Family Medicine, Alpert Medical School of Brown University, Providence, USA. ${ }^{3}$ Department of Epidemiology, Brown University School of Public Health, Providence, USA. ${ }^{4}$ Alpert Medical School of Brown University, Providence, USA.

Received: 17 August 2013 Accepted: 12 November 2014 Published: 5 December 2014

\section{References}

1. Mannino DM, Homa DM, Akinbami LJ, Ford ES, Redd SC: Chronic obstructive pulmonary disease surveillance-United States, 1971-2000. MMWR Surveill Summ 2002, 51(6):1-16.

2. Akinbami $L$, Liu X: Chronic obstructive pulmonary disease among adults aged 18 and over in the United States, 1998-2009. NCHS Data Brief 2011, (63):1-8.

3. Minino AM, Xu J, Kochanek KD: Deaths: Preliminary data for 2008. Natl Vital Stat Rep 2010, 59(2):1-52.

4. Barr RG, Celli BR, Mannino DM, Petty T, Rennard SI, Sciurba FC, Stoller JK, Thomashow BM, Turino GM: Comorbidities, patient knowledge, and disease management in a national sample of patients with COPD. Am J Med 2009, 122(4):348-355.

5. Jemal A, Ward E, Hao Y, Thun M: Trends in the leading causes of death in the United States, 1970-2002. J Am Med Assoc 2005, 294(10):1255-1259.

6. National Institutes of Health, National Heart Lung and Blood Institute: Morbility and Mortality: 2009 Chart Book on Cardiovascular, Lung, and Blood Diseases. Bethesda, MD: NHLBl; 2009.

7. Parimon T, Chien JW, Bryson CL, McDonell MB, Udris EM, Au DH: Inhaled corticosteroids and risk of lung cancer among patients with chronic obstructive pulmonary disease. Am J Respir Crit Care Med 2007, 175(7):712-719.
8. Sin D, Anthonisen N, Soriano JB, Agusti A: Mortality in COPD: role of comorbidities. Eur Respir J 2006, 28:1245-1257.

9. Huiart L, Ernst P, Suissa S: Cardiovascular morbidity and mortality in COPD. Chest 2005, 128(4):2640-2646.

10. Hansell AL, Walk JA, Soriano JB: What do chronic obstructive pulmonary disease patients die from? A multiple cause coding analysis. Eur Respir $\rfloor$ 2003, 22(5):809-814.

11. Ekstrom MP, Wagner P, Strom KE: Trends in cause-specific mortality in oxygen-dependent chronic obstructive pulmonary disease. Am J Respir Crit Care Med 2011, 183(8):1032-1036.

12. Sin DD, Man SF: Why are patients with chronic obstructive pulmonary disease at increased risk of cardiovascular diseases? The potential role of systemic inflammation in chronic obstructive pulmonary disease. Circulation 2003, 107(11):1514-1519.

13. Van Eeden S, Leipsic J, Paul Man SF, Sin DD: The relationship between lung inflammation and cardiovascular disease. Am J Respir Crit Care Med 2012, 186(1):11-16

14. Nussbaumer-Ochsner Y, Rabe KF: Systemic manifestations of COPD. Chest 2011, 139(1):165-173.

15. Sin DD, Man SF: Chronic obstructive pulmonary disease as a risk factor for cardiovascular morbidity and mortality. Proc Am Thorac Soc 2005, 2(1):8-11.

16. Ezzati TM, Massey JT, Waksberg J, Chu A, Maurer KR: Sample design: third national health and nutrition examination survey. Vital Health Stat 2 1992, (113):1-35.

17. National Center for Health Statistics: Plan and operation of the third national health and nutrition examination survey, 1988-1994. Series 1: Programs and Collection Procedures. Vital Health Stat 1 1994, 32:1-407.

18. American Thoracic Society: Standardization of Spirometry - 1987 update. Statement of the American Thoracic Society. Am Rev Respir Dis 1987, 136(5):1285-1298

19. National Center for Health Statistics: Office of Analysis and Epidemiology. The Third National Health and Nutrition Examination Survey (NHANES III) Linked Mortality file, Mortality Follow-up through 2006: Matching Methodology. Hyattsville, Maryland; 2009 (Available at the following address: http://www.cdc.gov/nchs/data/datalinkage/matching_ methodology nhanes 3 final.pdf).

20. Third National Health and Nutrition Examination Survey (NHANES III) Linked Mortality File Public-use file Layout. Available at: http:/www.cdc.gov/nchs/ data/datalinkage/nh3_file_layout_public_2010.pdf.

21. Gunter EW, Lewis BG, Koncikowski SM: Laboratory Procedures used for the Third National Health and Nutrition Examination Survey (NHANES III), 1988-1994. Atlantal Georgia: Centers for Disease Control and Prevention, National Center for Environmental Health, and National Center for Health Statistics; 1996.

22. Beddhu S, Baird BC, Zitterkoph J, Neilson J, Greene T: Physical activity and mortality in chronic kidney disease (NHANES III). Clin J Am Soc Nephrol 2009, 4(12):1901-1906.

23. Frohlich E: Recommendations for blood pressure determined by sphygmomanometry. Ann Intern Med 1988, 109(8):612.

24. National Center for Health Statistics: Third National Health and Nutrition Examination Survey III. Spirometry Procedure Manual. Rockville, MD: Westat Inc; 1988.

25. Global Initiative for Chronic Obstructive Lung Disease, Global Strategy for the Diagnosis, Management, and Prevention of Chronic Obstructive Lung Disease (GOLD). 2013. Available from: http://www.goldcopd.org/uploads/users/files/ GOLD_Report_2013_Feb20.pdf.

26. Hankinson JL, Odencrantz JR, Fedan KB: Spirometric reference values from a sample of the general U.S. population. Am J Respir Crit Care Med 1999, 159(1):179-187.

27. Grundy SM, Cleeman Jl, Merz CN, Brewer HB Jr, Clark LT, Hunninghake DB, Pasternak RC, Smith SC Jr, Stone NJ, National Heart Lung, Blood Institute, American College of Cardiology Foundation, American Heart Association: Implications of recent clinical trials for the national cholesterol education program adult treatment panel III guidelines. Circulation 2004, 110(2):227-239.

28. Hoenig MR: Implications of the obesity epidemic for lipid-lowering therapy: non-HDL cholesterol should replace LDL cholesterol as the primary therapeutic target. Vasc Health Risk Manage 2008, 4(1):143-156.

29. Araki A, Sako Y: Determination of free and total homocysteine in human plasma by high-performance liquid chromatography with fluorescence detection. J Chromatogr 1987, 422:43-52. 
30. Buckley DI, Fu R, Freeman M, Rogers K, Helfand M: C-reactive protein as a risk factor for coronary heart disease: a systematic review and meta-analyses for the U.S. Preventive Services Task Force. Ann Intern Med 2009, 151(7):483-495.

31. Visser M, Bouter LM, McQuillan GM, Wener MH, Harris TB: Elevated C-reactive protein levels in overweight and obese adults. J Am Med Assoc 1999, 282(22):2131-2135.

32. Wong ND, Pio J, Valencia R, Thakal G: Distribution of C-reactive protein and its relation to risk factors and coronary heart disease risk estimation in the National Health and Nutrition Examination Survey (NHANES) III. Prev Cardiol 2001, 4(3):109-114.

33. Barnes PJ, Celli BR: Systemic manifestations and comorbidities of COPD. Eur Respi J 2009, 33(5):1165-1185.

34. Gan WQ, Man SF, Senthilselvan A, Sin DD: Association between chronic obstructive pulmonary disease and systemic inflammation: a systematic review and a meta-analysis. Thorax 2004, 59(7):574-580.

35. Agusti A: Thomas a. Neff lecture. Chronic obstructive pulmonary disease: a systemic disease. Proc Am Thorac Soc 2006, 3(6):478-481.

36. Janda S, Park K, FitzGerald JM, Etminan M, Swiston J: Statins in COPD: a systematic review. Chest 2009, 136(3):734-743.

37. Ridker PM, Danielson E, Fonseca FA, Genest J, Gotto AM Jr, Kastelein JJ, Koenig W, Libby P, Lorenzatti AJ, MacFadyen JG, Nordestgaard BG, Shepard J, Willerson JT, Glynn RJ, Jupiter Study Group: Rosuvastatin to prevent vascular events in men and women with elevated C-reactive protein. N Engl J Med 2008, 359(21):2195-2207.

38. Mancini GB, Etminan M, Zhang B, Levesque LE, FitzGerald JM, Brophy JM: Reduction of morbidity and mortality by statins, angiotensin-converting enzyme inhibitors, and angiotensin receptor blockers in patients with chronic obstructive pulmonary disease. J Am Coll Cardiol 2006, 47(12):2554-2560.

39. Mortensen EM, Copeland LA, Pugh MJ, Restrepo MI, de Molina RM, Nakashima B, Anzueto A: Impact of statins and ACE inhibitors on mortality after COPD exacerbations. Respir Res 2009, 10:45.

40. Hansen JE, Sun XG, Wasserman K: Spirometric criteria for airway obstruction: Use percentage of FEV1/FVC ratio below the fifth percentile, not $<70 \%$. Chest 2007, 131(2):349-355.

doi:10.1186/1471-2466-14-195

Cite this article as: Parker et al: Is inflammatory chronic obstructive pulmonary disease a coronary heart disease risk equivalent? A longitudinal analysis of the third National Health and Nutrition Examination Survey (NHANES III), 1988-1994. BMC Pulmonary Medicine 2014 14:195.

\section{Submit your next manuscript to BioMed Central and take full advantage of:}

- Convenient online submission

- Thorough peer review

- No space constraints or color figure charges

- Immediate publication on acceptance

- Inclusion in PubMed, CAS, Scopus and Google Scholar

- Research which is freely available for redistribution 